\section{THE LINK BETWEEN COSMETIC DENTISTRY AND ORTHODONTICS}

GDPs thinking of expanding into the field of minimally invasive cosmetic dentistry by becoming Inman Aligner providers should hurry - there are only two more chances left to register for the popular Inman Aligner Hands-on Certification course this year.

The Straight Talk one day certified intensive training course provides clinicians with the necessary training to become certified Inman Aligner providers and begin handling simple to moderate cases immediately after training.

The Inman Aligner, which has been described as the 'missing link' between cosmetic dentistry and orthodontics, is currently the fastest way to straighten anterior teeth in a non-invasive, lifestyle-friendly manner. Only two training dates currently remain available,

\title{
SAVE CLINICAL TIME AND TOOTH STRUCTURE
}

SDI's Riva Silver glass ionomer is reinforced with silver alloy and is ideal for use as an inter-appointment dressing

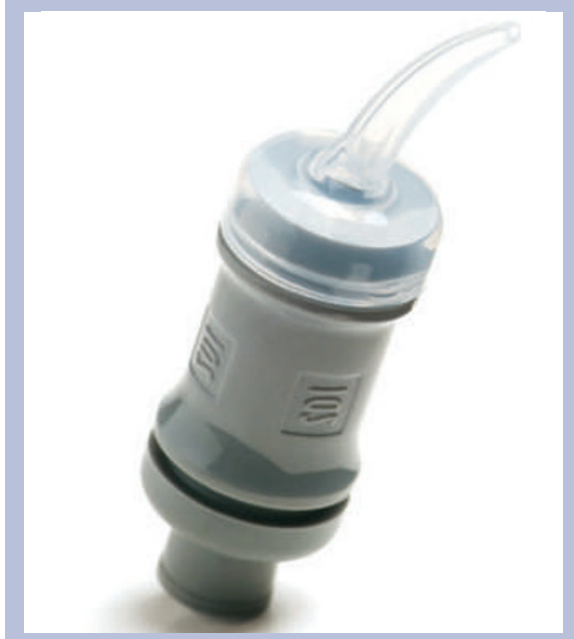

material in endodontic procedures. The high colour contrast of Riva Silver glass ionomer with the tooth makes it very easy to remove between visits. Riva Silver's natural sealing ability and high fluoride release protect the tooth chamber from unwanted oral bacteria.

Glass ionomer cements are becoming more and more popular due to their ability to bond to dentine and their biocompatibility, high radiopacity and excellent fluoride release. They save clinical time and tooth structure during removal.

Riva Silver is supplied in pre-dosed capsules and hand mix presentations. Reader response number 61 due to take place in London on 16 0ctober 2010 and 21 January 2011. A one day seminar in Copenhagen is also planned for 29 0ctober 2010 for those who cannot make the UK dates.

If you are looking for a guaranteed way to safely and quickly expand your practice and provide patients with an increasingly desirable way to achieve their dream smile, then this is your chance.

Reader response number 60

\section{ENDODONTIC ROADSHOW}

Clinicians with an interest in endodontics should not miss DENTSPLY's 2010 Endodontic Roadshow during September, where they can gain the latest advice on how to use some of the market's leading endodontic products such as ProTaper, along with recent innovations including PathFiles and the Calamus Dual.

Supported by the Dental Defence Union and hosted over one and a half days and at four venues, internationally renowned speaker Dr Arnaldo Castellucci will be joined by a guest speaker at each event.

Dates and venues include 15 and 16 September in Manchester, 17 and 18 September in Edinburgh, 20 and 21 September in Dublin and 22 and 23 September in Cardiff.

Reader response number 62

canals, helps clinicians perform safer, more accurate root canal treatment.

NSK provide clinicians with an unbeatable combination of endodontic instruments and equipment, guaranteeing safer canal interventions and improving patient comfort.

\section{Reader response number 63}

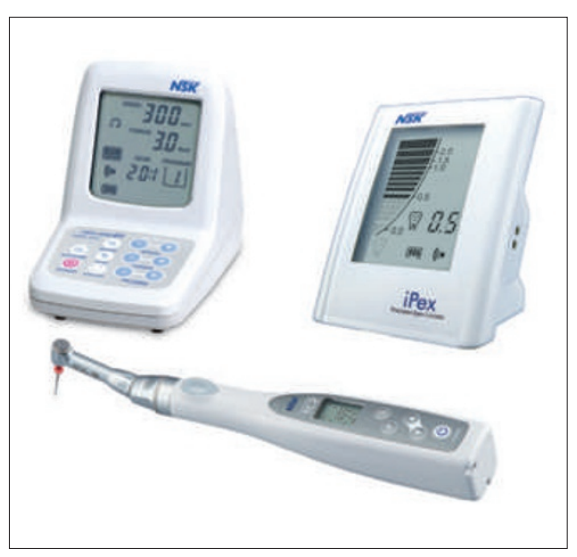

